\title{
An Efficient Process for Pretreatment of Lignocelluloses in Functional Ionic Liquids
}

\author{
Shi-Jia Dong, ${ }^{1}$ Bi-Xian Zhang, ${ }^{2}$ Yun-Fei Gao, ${ }^{2}$ and Xiao-Mei $\mathrm{Hu}^{3}$ \\ ${ }^{1}$ College of Agriculture, Northeast Agricultural University, Harbin 150030, China \\ ${ }^{2}$ Heilongjiang Academy of Agricultural Sciences, Harbin 150086, China \\ ${ }^{3}$ College of Life Science, Northeast Agricultural University, Harbin 150030, China
}

Correspondence should be addressed to Xiao-Mei Hu; huxiaomei1982@163.com

Received 11 June 2015; Accepted 6 August 2015

Academic Editor: Huining Xiao

Copyright (C) 2015 Shi-Jia Dong et al. This is an open access article distributed under the Creative Commons Attribution License, which permits unrestricted use, distribution, and reproduction in any medium, provided the original work is properly cited.

\begin{abstract}
Background and Aims. The complex structure of the lignocelluloses is the main obstacle in the conversion of lignocellulosic biomass into valuable products. Ionic liquids provide the opportunities for their efficient pretreatment for biomass. Therefore, in this work, pretreatment of corn stalk was carried out in ultrasonic-assisted ionic liquid including 1-butyl-3-methylimidazolium chloride [BMIM]Cl, 1-H-3-methylimidazolium chloride [HMIM]Cl, and 1-(1-propylsulfonic)-3-imidazolium chloride $\left[\mathrm{HSO}_{3}-\mathrm{pMIM}^{\mathrm{C}} \mathrm{Cl}\right.$ at $70^{\circ} \mathrm{C}$ for $2 \mathrm{~h}$. We compared the pretreatments by ionic liquid with and without the addition of deionized water. Fourier transform infrared spectroscopy (FTIR) and scanning electron microscopy (SEM) were employed to analyze the chemical characteristics of regenerated cellulose-rich materials. Results. [HMIM]Cl and $\left[\mathrm{HSO}_{3}\right.$-pMIM]Cl were effective in lignin extraction to obtain cellulose-rich materials. FTIR analysis and SEM analysis indicated the effective lignin removal and the reduced crystallinity of cellulose-rich materials. Enzymatic hydrolysis of cellulose-rich materials was performed efficiently. High yields of reducing sugar and glucose were obtained when the corn stalk was pretreated by [HMIM]Cl and $\left[\mathrm{HSO}_{3}-\mathrm{pMIM}\right] \mathrm{Cl}$. Conclusions. Ionic liquids provided the ideal environment for lignin extraction and enzymatic hydrolysis of corn stalk and [HMIM]Cl and $\left[\mathrm{HSO}{ }_{3}-\mathrm{pMIM}\right] \mathrm{Cl}$ proved the most efficient ionic liquids. This simple and environmentally acceptable method has a great potential for the preparation of bioethanol for industrial production.
\end{abstract}

\section{Introduction}

Biofuels produced from biomass have attracted much attention in recent years due to the awareness of energy crisis and global warming. Lignocellulosic biomass is increasingly promoted as environmentally and economically sustainable fuel with a high potential as it is abundant form of biomass and nonfood source for the bioethanol production [1]. During the process of lignocellulose-to-biofuel, the complex structure of the lignocelluloses is the main obstacle in lignocellulosic conversion [2]. Pretreatment of lignocelluloses in high temperature and high pressure is always required in order to break the lignocellulosic structure to make its cellulose available for enzymatic hydrolysis. It is necessary to develop alternative new techniques.
In recent years, ionic liquids (ILs) have gained wide popularity for their increasing applications as they possess a number of interesting properties such as low vapor pressure, high thermal stability, and lack of flammability. In 2002, Rogers group reported the dissolution of cellulose in ILs with the cation of 1-butyl-3-methylimidazolium ([BMIM]) and the anion of $\mathrm{Cl}^{-}, \mathrm{Br}^{-}$, or $\mathrm{SCN}^{-}$at $100^{\circ} \mathrm{C}$ [3]. As follows, studies of cellulose in ILs with the cation of [BMIM] and the anion of chloride, bromide, acetate, or formate are reported. It is also described that the pretreatment with ILs can reduce the crystallinity of cellulose and partially remove hemicelluloses and lignin [2]. Currently, Nasirpour et al. reported the pretreatment of sugarcane bagasse by $[\mathrm{BMIM}] \mathrm{Cl}$ at $130^{\circ} \mathrm{C}$ for $90 \mathrm{~min}$ [4]. Aver et al. reported the pretreatment of sugarcane bagasse by $[\mathrm{EMIM}] \mathrm{CH}_{3} \mathrm{COO}$, $[\mathrm{BMIM}] \mathrm{CH}_{3} \mathrm{COO}$, 
[BMIM]Cl, [BMIM]Br, and [BMIM] $\mathrm{CH}_{3} \mathrm{SO}_{4}$ at $80^{\circ} \mathrm{C}$ and $120^{\circ} \mathrm{C}$ for a period of $24 \mathrm{~h}$ [5]. Ma et al. reported the combined use of ultrasound irradiation and [BMIM] Cl as a potential alternative method in the preparation of glutarates from sugarcane bagasse [1]. However, most studies focused on the pretreatment of lignocelluloses by ionic liquids including [AMIM]Cl, [BMIM]Cl, and [EMIM] $\mathrm{CH}_{3} \mathrm{COO}$. High pretreatment temperatures and long pretreatment time are always required in current studies. With the aim of producing more efficient ionic liquids for the treatment of agricultural lignocellulosic materials, ionic liquids including 1-butyl-3-methylimidazolium chloride [BMIM]Cl, 1-H-3-methylimidazolium chloride [HMIM]Cl, and 1-(1propylsulfonic)-3-imidazolium chloride $\left[\mathrm{HSO}_{3}-\mathrm{pMIM}\right] \mathrm{Cl}$ were investigated.

\section{Materials and Methods}

2.1. Materials. All chemicals were purchased from Aladdin Company (China) and used as received. Cellulase (10000 U/mg) was purchased from Aladdin Company. The corn stalk supplied by local farm in Harbin City (China) was milled to pass through 40 mesh sieves and dried at $60^{\circ} \mathrm{C}$ for $24 \mathrm{~h}$ prior to use. [BMIM]Cl, [HMIM] Cl, and $\left[\mathrm{HSO}_{3}-\mathrm{pMIM}\right] \mathrm{Cl}$ were prepared as described $[6,7]$. Treatment of corn stalk was performed in KQ-400KDE ultrasound (Kunshan). Analysis of reducing sugar was performed on UV-mini-1240 spectrometer (SHIMADZU). Fourier transform infrared spectroscopy (FTIR) was analyzed on FTIR-8400S spectrometer (SHIMADZU, Japan) in the range of $4000-400 \mathrm{~cm}^{-1}$. Scanning electron microscopy (SEM) was performed on S-3400N (HITACHI). HPLC analysis was performed on WATERS 2695. The composition of corn stalk was determined according to the standard NREL method [8]. There are $21.34 \%$ of lignin, $20.31 \%$ of hemicelluloses, $43.11 \%$ of cellulose, and $0.75 \%$ of ash.

2.2. Ionic Liquid Treatment. The treatment of corn stalk in ionic liquids was conducted in $50 \mathrm{~mL}$ vessels placed under ultrasound irradiation $(400 \mathrm{~W})$. About $0.2 \mathrm{~g}$ of cotton stalk with or without $1 \mathrm{~mL}$ of deionized water was rapidly added into $5 \mathrm{~g}$ of one of the ionic liquids for $120 \mathrm{~min}$ at $70^{\circ} \mathrm{C}$. When [BMIM]Cl was used, $2 \mathrm{~mL}$ of DMSO was added into [BMIM]Cl. After pretreatment by ionic liquid, $20 \mathrm{~mL}$ of an antisolvent (deionized water/acetone, $1 / 1, \mathrm{v} / \mathrm{v}$ ) was added into the mixture. The filtrate was measured for sugar analysis. The solid was filtered out, washed with $30 \mathrm{~mL}$ of water/acetone $(1 / 1, v / v)$, and then dried in a vacuum at $60^{\circ} \mathrm{C}$ for $24 \mathrm{~h}$ to give the cellulose-rich materials. When acetone was evaporated, lignin precipitated out in $\mathrm{IL} / \mathrm{H}_{2} \mathrm{O}$ solution. The regenerated lignin was filtered out, washed with deionized water, and dried under vacuum at $60^{\circ} \mathrm{C}$ for $24 \mathrm{~h}$ :

$$
\begin{aligned}
\text { The cellulose-rich materials or lignin }(\%)= & \left(\frac{\text { the weight of cellulose-rich materials or lignin }(\mathrm{g})}{\text { the weight of untreated corn stalk subjected to pretreatment }(\mathrm{g})}\right) \\
& \times 100 \% .
\end{aligned}
$$

2.3. Determination of the Reducing Sugar. The filtrate from 2.2 was neutralized by the addition of solid of sodium hydroxide. The amount of reducing sugar was measured using the 3,4-dinitrosalicylic acid (DNS) method [9]. The concentration of reducing sugar was calculated by employing a standard curve prepared using glucose and the absorbance was measured at $540 \mathrm{~nm}$ using UV spectrometer:

$$
\begin{aligned}
\text { Reducing sugar during pretreatment }(\%)= & \left(\frac{\text { the weight of reducing sugar in the filtrate }(\mathrm{g})}{\text { the weight of untreated corn stalk subjected to pretreatment }(\mathrm{g})}\right) \\
& \times 100 \% .
\end{aligned}
$$

2.4. Enzymatic Hydrolysis. Enzymatic hydrolysis of untreated or IL-treated samples was carried out with a biomass loading of $1 \%(\mathrm{~g} / \mathrm{mL})$ in $0.05 \mathrm{M}$ sodium citrate buffer at $\mathrm{pH} 4.8$ and $50^{\circ} \mathrm{C}$ in a water shaker incubator at $200 \mathrm{rpm} .5 \mathrm{~mL}$ of cellulase was used at a loading of $4000 \mathrm{U} / \mathrm{g}$. The enzymatic reaction proceeded for $12 \mathrm{~h}$ and was then quenched after stirring at $100^{\circ} \mathrm{C}$ for $10 \mathrm{~min}$. After that, the mixture was filtered out and the filtrate was neutralized by the addition of solid of sodium hydroxide. The reducing sugars were analyzed via DNS method [9]:

Enzymatic reducing sugar $(\%)=\left(\frac{\text { the weight of reducing sugar after enzymatic hydrolysis }(\mathrm{g})}{\text { the weight of cellulose-rich materials subjected to pretreatment }(\mathrm{g})}\right) \times 100 \%$. 


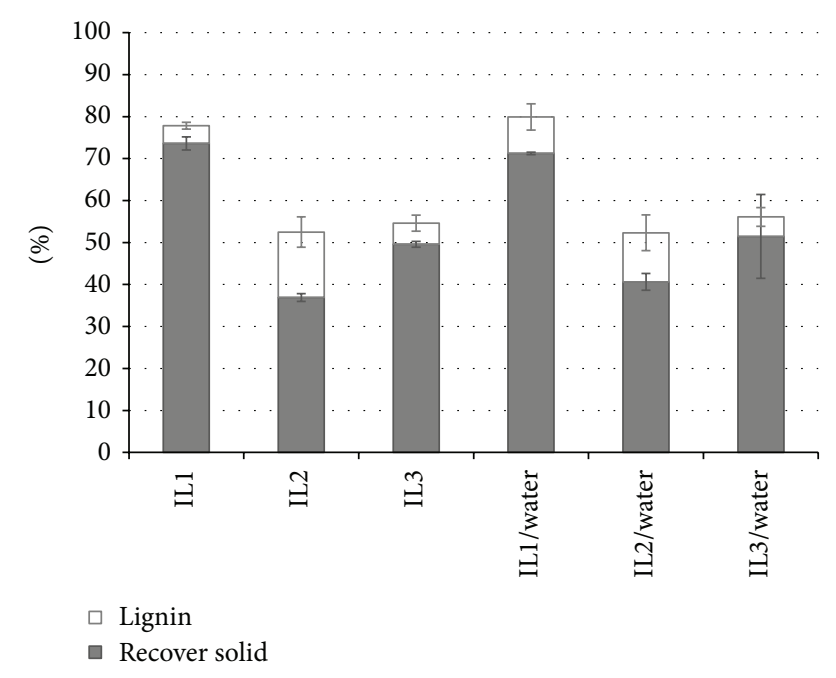

FIgURE 1: Yields of IL-isolated lignin and cellulose-rich materials. IL1: [BMIM]Cl/DMSO, IL2: [HMIM] Cl, and IL3: [ $\mathrm{HSO}_{3}$-pMIM] Cl.

\section{Results and Discussion}

In this work, pretreatment of corn stalk performed in IL and $\mathrm{IL} / \mathrm{H}_{2} \mathrm{O}$ was investigated. Due to the solid form of [BMIM] Cl at reaction conditions, DMSO was added into [BMIM]Cl, which can decrease the viscosity of ionic liquid and benefit the pretreatment process [10]. After pretreatment with one of the ionic liquids, a solution of water/acetone (1:1) was added into the mixture and the solid was filtered out to give cellulose-rich materials. As presented in Figure 1, about 73\% of cellulose-rich materials were obtained when corn stalk was treated by [BMIM]Cl. About $37 \%$ and $50 \%$ of celluloserich materials were achieved when the corn stalk was treated by $[\mathrm{HMIM}] \mathrm{Cl}$ and $\left[\mathrm{HSO}_{3}-\mathrm{pMIM}\right] \mathrm{Cl}$, respectively, which indicated that most lignin was isolated by [HMIM]Cl.

The presence of lignin limits cellulase reaching to cellulose; thus, lignin removal is important to conduct an efficient cellulose conversion. As shown in Figure 1, higher lignin was obtained when corn stalk was pretreated with only IL compared to that treated with $\mathrm{IL} / \mathrm{H}_{2} \mathrm{O}$, which was probably because the dissolution of lignin from corn stalk was decreased when water was added. A high yield of lignin was obtained when the corn stalk was pretreated with [HMIM]Cl and $\left[\mathrm{HSO}_{3}\right.$-pMIM]Cl. A low yield was observed using [BMIM]Cl. As reported, ionic liquids including [BMIM]Cl, [EMIM]COOH have been successfully employed for their ability to remove lignin. Li et al. reported $69.2 \%$ total lignin removal from switchgrass using [EMIM] COOH at $160^{\circ} \mathrm{C}$ for $3 \mathrm{~h}$ [11]. Liu et al. described that the lignin of untreated cole stalk was $17.71 \%$ and it reduced to $12.35 \%$ after being treated by [BMIM] $\mathrm{Cl}$ at $145^{\circ} \mathrm{C}$ for $15 \mathrm{~min}$ [12]. In this work, $15.59 \%$ of lignin was obtained when the corn stalk was pretreated by only [HMIM]Cl without deionized water at $70^{\circ} \mathrm{C}$ for $2 \mathrm{~h}$, corresponding to $73 \%$ in the original lignin of corn stalk.

Actually, when water was added into the pretreatment process, hydrolysis of cellulose and hemicelluloses occurred. As shown in Figure 2, a high yield of reducing sugar was obtained with the pretreatment by $\mathrm{IL} / \mathrm{H}_{2} \mathrm{O}$. A low yield of

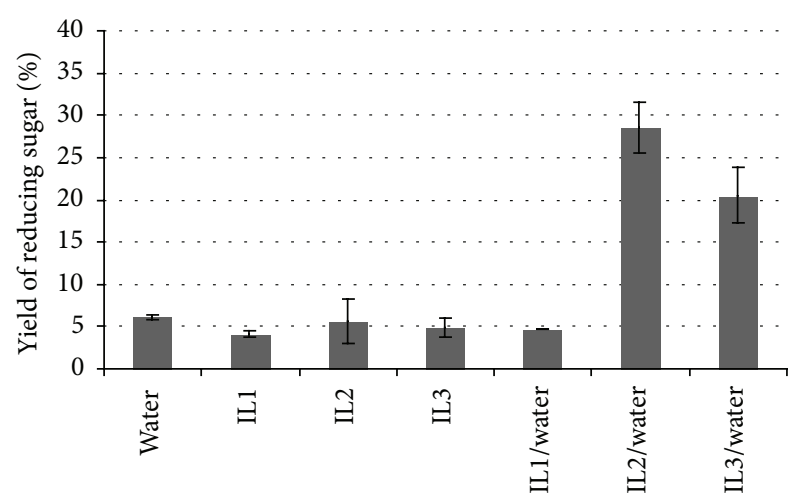

FIgURE 2: Yields of reducing sugar in the pretreatment. IL1: [BMIM]Cl/DMSO, IL2: [HMIM]Cl, and IL3: $\left[\mathrm{HSO}_{3}-\mathrm{pMIM}\right] \mathrm{Cl}$.

reducing sugar was observed with the pretreatment by only IL. High yields of reducing sugar specially were obtained when corn stalk was treated by $[\mathrm{HMIM}] \mathrm{Cl} / \mathrm{H}_{2} \mathrm{O}$ or $\left[\mathrm{HSO}_{3}\right.$ pMIM]Cl/ $\mathrm{H}_{2} \mathrm{O}$. Poor yield was found when corn stalk was pretreated by [BMIM] Cl/DMSO/ $\mathrm{H}_{2} \mathrm{O}$, probably due to the weak basic property of [BMIM] Cl, which could not induce the effective hydrolysis of the corn stalk. Reducing sugar was comparable when the corn stalk was treated by only water or ionic liquid.

3.1. SEM Analysis. SEM was employed to examine the structural change of untreated and pretreated corn stalk in morphology before and after IL pretreatment. As shown in Figure 3, the compact ordered and rigid fibril structure was observed in untreated corn stalk. After pretreatment of corn stalk with ionic liquids, the structure became loose disordered, which was probably due to the removal of lignin and decrease of cellulose crystallinity. Pretreatment with IL and $\mathrm{IL} / \mathrm{H}_{2} \mathrm{O}$ caused slight modifications on the structure of corn stalk. Pretreatment with $[\mathrm{HMIM}] \mathrm{Cl}$ and $\left[\mathrm{HSO}_{3}-\right.$ pMIM]Cl induced considerable changes (Figure 3).

3.2. FTIR Analysis. FTIR analysis was conducted to examine the structure of untreated, IL-treated, and $\mathrm{IL} / \mathrm{H}_{2} \mathrm{O}$-treated corn stalk. As presented in Figure 4, the peaks at 3422, $2918,1430,1371,1318,1162,1112,1069$, and $897 \mathrm{~cm}^{-1}$ are associated with cellulose. The peak at $3422 \mathrm{~cm}^{-1}$ is attributed to $\mathrm{O}-\mathrm{H}$ stretching. The absorption at $2918 \mathrm{~cm}^{-1}$ is attributed to $\mathrm{C}-\mathrm{H}$ stretching. A peak at $1430 \mathrm{~cm}^{-1}$ is associated with $\mathrm{CH}_{2}$ symmetric bending. $1371 \mathrm{~cm}^{-1}$ is associated with $\mathrm{C}$ $\mathrm{H}$ bending. $1318 \mathrm{~cm}^{-1}$ is associated with $\mathrm{CH}_{2}$ bending of carbohydrates. The peak at $1162 \mathrm{~cm}^{-1}$ is attributed to C$\mathrm{O}$ antisymmetric stretching. A band at $1112 \mathrm{~cm}^{-1}$ is related to $\mathrm{C}-\mathrm{OH}$ skeletal vibration. A peak at $1069 \mathrm{~cm}^{-1}$ is due to the $\mathrm{C}-\mathrm{O}-\mathrm{C}$ pyranose ring skeletal vibration. The peak at $897 \mathrm{~cm}^{-1}$ corresponds to the glycosidic C1-H deformation with ring vibration contribution, which is a characteristic of $\beta$-glycosidic linkages between glucose molecules in cellulose.

As shown in Figure 4, a strong peak at $1733 \mathrm{~cm}^{-1}$ (Line 1) was attributed to the presence of unconjugated carbonyl and acetyl groups of hemicelluloses in untreated corn stalk. This 


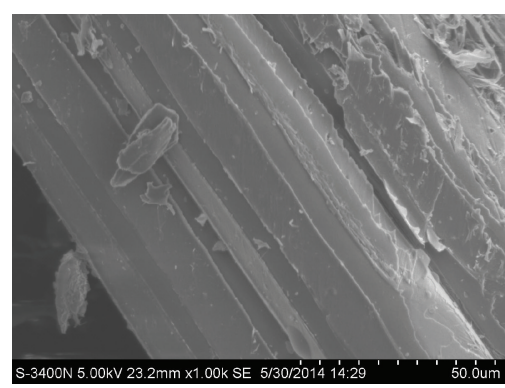

(a)

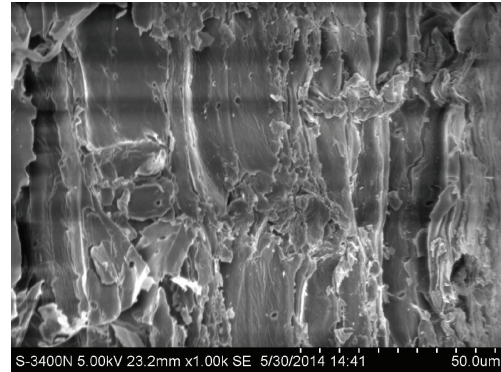

(b)

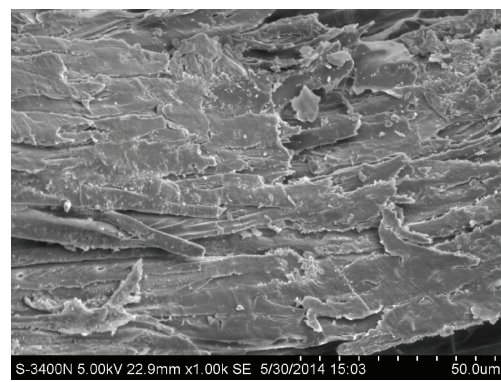

(c)

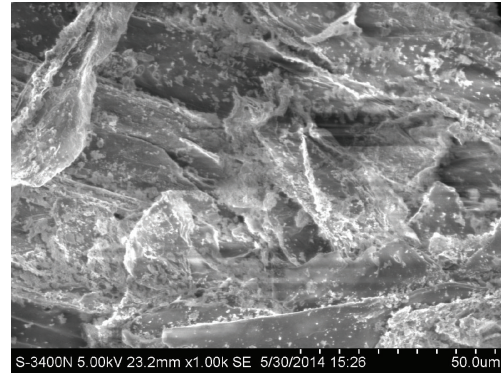

(d)

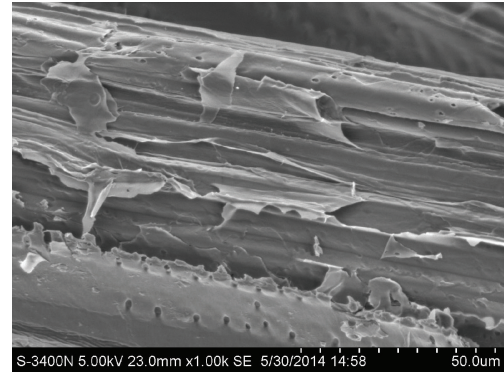

$\left(\mathrm{b}^{\prime}\right)$

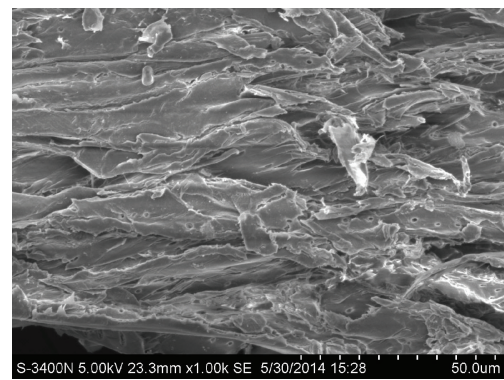

(c')

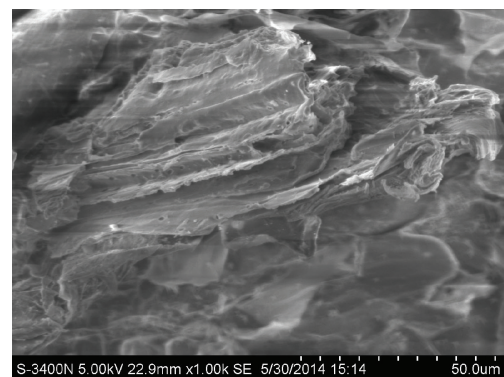

$\left(d^{\prime}\right)$

FIGURE 3: SEM analysis of corn stalk and cellulose-rich materials. (a) Untreated corn stalk; (b) [BMIM]Cl/DMSO; (c) [HMIM]Cl; (d) [HSO ${ }_{3}$ pMIM]Cl; (b') [BMIM]Cl/DMSO/ $\mathrm{H}_{2} \mathrm{O}$; (c') $[\mathrm{HMIM}] \mathrm{Cl} / \mathrm{H}_{2} \mathrm{O}$; (d') $\left[\mathrm{HSO}_{3}-\mathrm{pMIM}\right] \mathrm{Cl} / \mathrm{H}_{2} \mathrm{O}$.

peak intensity was significantly reduced after the pretreatment by [HMIM] Cl and [ $\left.\mathrm{HSO}_{3}-\mathrm{pMIM}\right] \mathrm{Cl}$, which indicated that hemicelluloses were decreased effectively; however, no obvious reduction was observed with the pretreatment by [BMIM]Cl. The peak at $1430 \mathrm{~cm}^{-1}$ (Line 2) can be assigned to bending vibration of $\mathrm{CH}_{2}$ that is strong in crystalline cellulose and weak in amorphous cellulose [13]. The $\mathrm{CH}_{2}$ band was weaker after the sample was pretreated by [HMIM]Cl and $\left[\mathrm{HSO}_{3}-\mathrm{pMIM}\right] \mathrm{Cl}$, which implied that the crystallinity of cellulose-rich materials was reduced. The intensity of peak at $1250 \mathrm{~cm}^{-1}$ (Line 3) assigned as $\mathrm{C}-\mathrm{O}$ stretching signal in lignin and hemicelluloses was also reduced indicating the decreased lignin and hemicelluloses [11]. In addition, the peak at $897 \mathrm{~cm}^{-1}$ (Line 4) corresponds to the glycosidic $\mathrm{C} 1-\mathrm{H}$ deformation with ring vibration contribution, which is a characteristic of $\beta$-glycosidic linkages between glucose molecules in cellulose [14]. This peak was obvious after the pretreatment by ionic liquids, especially [HMIM]Cl 


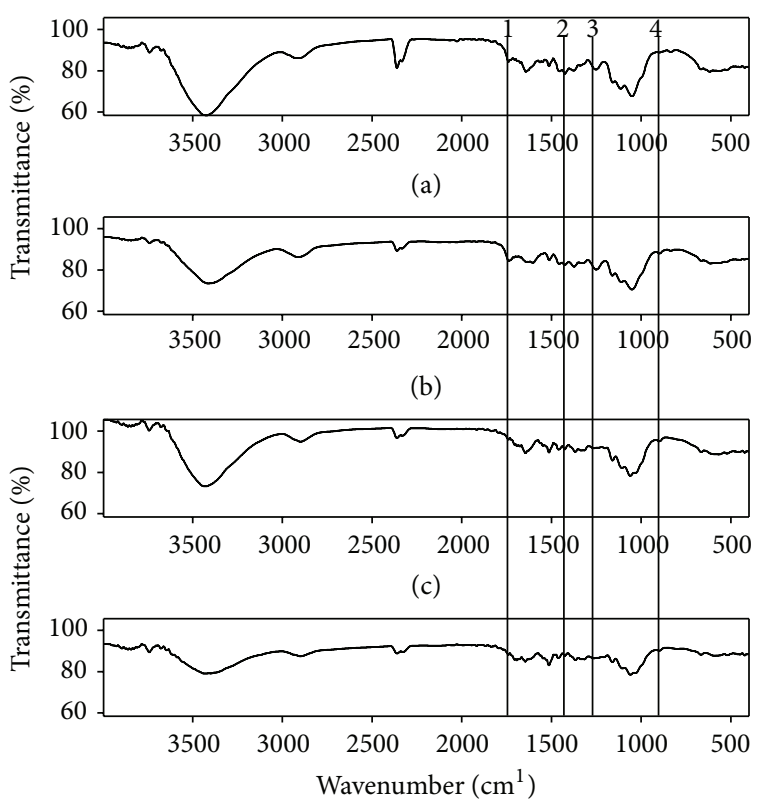

(d)

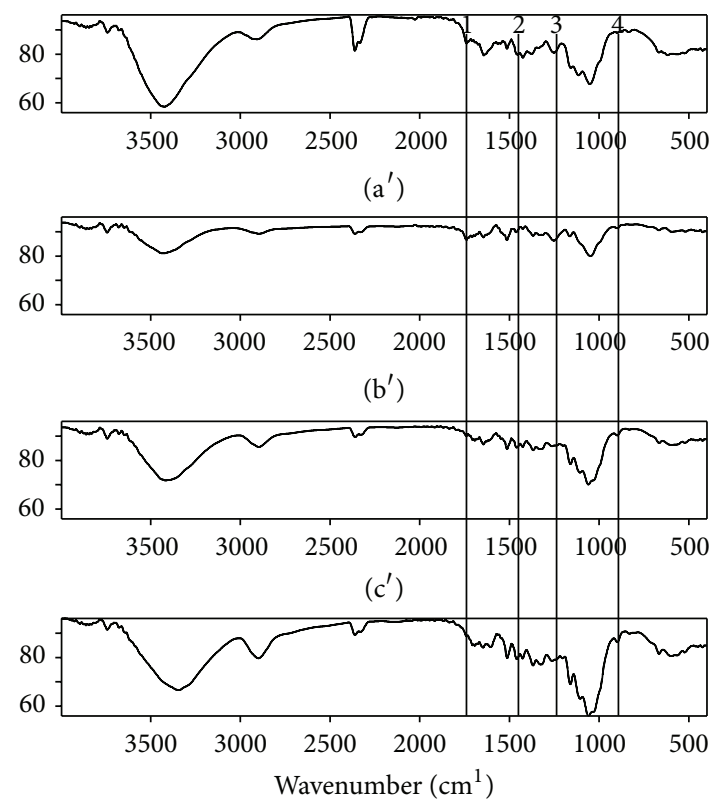

$\left(d^{\prime}\right)$

FIGURE 4: FTIR spectra of corn stalk and cellulose-rich materials: (a) untreated corn stalk; (b) [BMIM]Cl/DMSO; (c) [HMIM]Cl; (d) [HSO ${ }_{3}^{-}$ pMIM] $\mathrm{HSO}_{3} ;\left(\mathrm{a}^{\prime}\right)$ untreated corn stalk; $\left(\mathrm{b}^{\prime}\right)[\mathrm{BMIM}] \mathrm{Cl} / \mathrm{DMSO} / \mathrm{H}_{2} \mathrm{O} ;\left(\mathrm{c}^{\prime}\right)[\mathrm{HMIM}] \mathrm{Cl}_{2} / \mathrm{H}_{2} \mathrm{O} ;\left(\mathrm{d}^{\prime}\right)\left[\mathrm{HSO}_{3}-\mathrm{pMIM}\right] \mathrm{Cl} / \mathrm{H}_{2} \mathrm{O}$.

and $\left[\mathrm{HSO}_{3}\right.$-pMIM]Cl indicating the reduced crystallinity of cellulose.

3.3. Enzymatic Hydrolysis of Corn Stalk. Enzymatic hydrolysis of untreated, IL-treated, and $\mathrm{IL} / \mathrm{H}_{2} \mathrm{O}$-treated corn stalk and cellulose-rich materials after $12 \mathrm{~h}$ was summarized in Figure 5. Significantly high yield of reducing sugar was observed in the samples treated by $[\mathrm{HMIM}] \mathrm{Cl}$ and $\left[\mathrm{HSO}_{3}\right.$ pMIM]Cl, possibly because most of lignin was removed and the crystalline structure was decreased when corn stalk was pretreated by ionic liquid. After $12 \mathrm{~h}$, a yield of $42 \%$ and $39 \%$ of reducing sugar was obtained when the corn stalk was treated by $[\mathrm{HMIM}] \mathrm{Cl}$ and $\left[\mathrm{HSO}_{3}-\mathrm{pMIM}\right] \mathrm{Cl}$, respectively. Then enzymatic hydrolysis time was increased to $72 \mathrm{~h}$. After $72 \mathrm{~h}, 85 \%$ and $81 \%$ of reducing sugar were achieved for $[\mathrm{HMIM}] \mathrm{Cl}$ and $\left[\mathrm{HSO}_{3}-\mathrm{pMIM}\right] \mathrm{Cl}$, respectively. Sugar analysis was conducted by HPLC. There are $75 \%$ of glucose and $12 \%$ of cellobiose for the pretreated sample by [HMIM]Cl after $72 \mathrm{~h}$. The considerable lignin removal and the reduction of cellulose crystalline of corn stalk benefited the effective enzymatic digestibility.

\section{Conclusion}

In conclusion, ionic liquids provided the ideal environment for lignin extraction and enzymatic hydrolysis for corn stalk. [HMIM] Cl and $\left[\mathrm{HSO}_{3}\right.$-pMIM] Cl were proved as the most efficient ionic liquids as pretreated solvents to remove lignin and give the recovery biomass for enzymatic hydrolysis. This simple and environmentally acceptable method has a great potential for the preparation of bioethanol for industrial production.

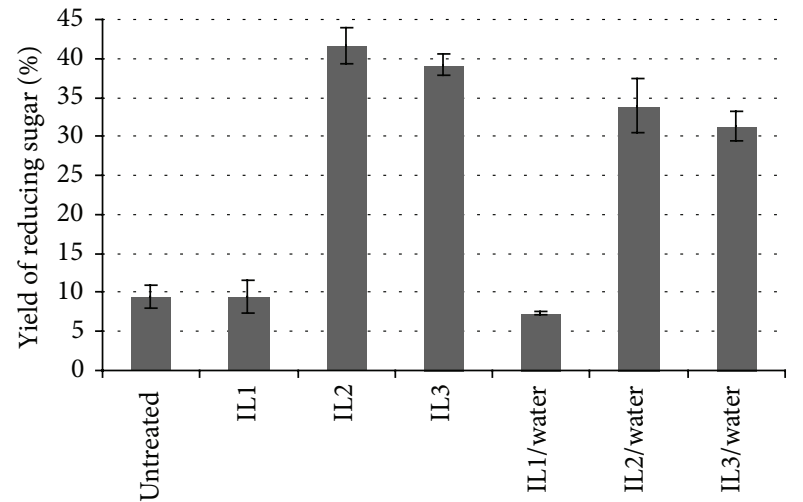

FIGURE 5: Yields of reducing sugar after enzymatic hydrolysis. IL1: [BMIM]Cl/DMSO, IL2: [HMIM]Cl, and IL3: $\left[\mathrm{HSO}_{3}-\mathrm{pMIM}\right] \mathrm{Cl}$.

\section{Conflict of Interests}

The authors declare that there is no conflict of interests regarding the publication of this paper.

\section{Authors' Contribution}

Bi-Xian Zhang and Shi-Jia Dong contributed equally to this work; both of them are first authors.

\section{Acknowledgments}

This work was financially supported by Heilongjiang Natural Science Foundation (QC2015007) and Heilongjiang Postdoctoral Foundation (LBH-Q13019). 


\section{References}

[1] S. Ma, X.-L. Xue, S.-J. Yu, and Z.-H. Wang, "High-intensity ultrasound irradiated modification of sugarcane bagasse cellulose in an ionic liquid," Industrial Crops and Products, vol. 35, no. 1, pp. 135-139, 2012.

[2] S. H. Lee, T. V. Doherty, R. J. Linhardt, and J. S. Dordick, "Ionic liquid-mediated selective extraction of lignin from wood leading to enhanced enzymatic cellulose hydrolysis," Biotechnology and Bioengineering, vol. 102, no. 5, pp. 1368-1376, 2009.

[3] R. P. Swatloski, S. K. Spear, J. D. Holbrey, and R. D. Rogers, "Dissolution of cellose with ionic liquids," Journal of the American Chemical Society, vol. 124, no. 18, pp. 4974-4975, 2002.

[4] N. Nasirpour, S. M. Mousavi, and S. A. Shojaosadati, "A novel surfactant-assisted ionic liquid pretreatment of sugarcane bagasse for enhanced enzymatic hydrolysis," Bioresource Technology, vol. 169, pp. 33-37, 2014.

[5] K. R. Aver, A. Z. Scortegagna, R. C. Fontana, and M. Camassola, "Saccharification of ionic-liquid-pretreated sugar cane bagasse using Penicillium echinulatum enzymes," Journal of the Taiwan Institute of Chemical Engineers, vol. 45, no. 5, pp. 2060-2067, 2014.

[6] A. S. Amarasekara and O. S. Owereh, "Hydrolysis and decomposition of cellulose in brönsted acidic ionic liquids under mild conditions," Industrial and Engineering Chemistry Research, vol. 48, no. 22, pp. 10152-10155, 2009.

[7] X. Hu, Y. Xiao, K. Niu, Y. Zhao, B. Zhang, and B. Hu, "Functional ionic liquids for hydrolysis of lignocellulose," Carbohydrate Polymers, vol. 97, no. 1, pp. 172-176, 2013.

[8] A. Sluiter, B. Hames, R. Ruiz et al., "Determination of structural carbohydrates and lignin in biomass," Laboratory Analytical Procedure (LAP) NREL/TP-510-42628, 2011.

[9] G. L. Miller, "Use of dinitrosalicylic acid reagent for determination of reducing sugar," Analytical Chemistry, vol. 31, no. 3, pp. 426-428, 1959.

[10] A. Xu, Y. Zhang, Y. Zhao, and J. Wang, "Cellulose dissolution at ambient temperature: role of preferential solvation of cations of ionic liquids by a cosolvent," Carbohydrate Polymers, vol. 92, no. 1, pp. 540-544, 2013.

[11] C. Li, B. Knierim, C. Manisseri et al., "Comparison of dilute acid and ionic liquid pretreatment of switchgrass: biomass recalcitrance, delignification and enzymatic saccharification," Bioresource Technology, vol. 101, no. 13, pp. 4900-4906, 2010.

[12] L. Liu, K. Niu, C. Liu, and F. Bai, "Effect of ionic liquid pretreatment on lignocellulosic biomass from oilseeds," CIESC Journal, vol. 64, supplement 1, pp. 104-110, 2013.

[13] M. L. Nelson and R. T. O'Connor, "Relation of certain infrared bands to cellulose crystallinity and crystal latticed type. Part I. Spectra of lattice types I, II, III and of amorphous cellulose," Journal of Applied Polymer Science, vol. 8, no. 3, pp. 1311-1324, 1964.

[14] C. Pappas, P. A. Tarantilis, I. Daliani, T. Mavromoustakos, and M. Polissiou, "Comparison of classical and ultrasoundassisted isolation procedures of cellulose from kenaf (Hibiscus cannabinus L.) and eucalyptus (Eucalyptus rodustrus Sm.)," Ultrasonics Sonochemistry, vol. 9, no. 1, pp. 19-23, 2002. 

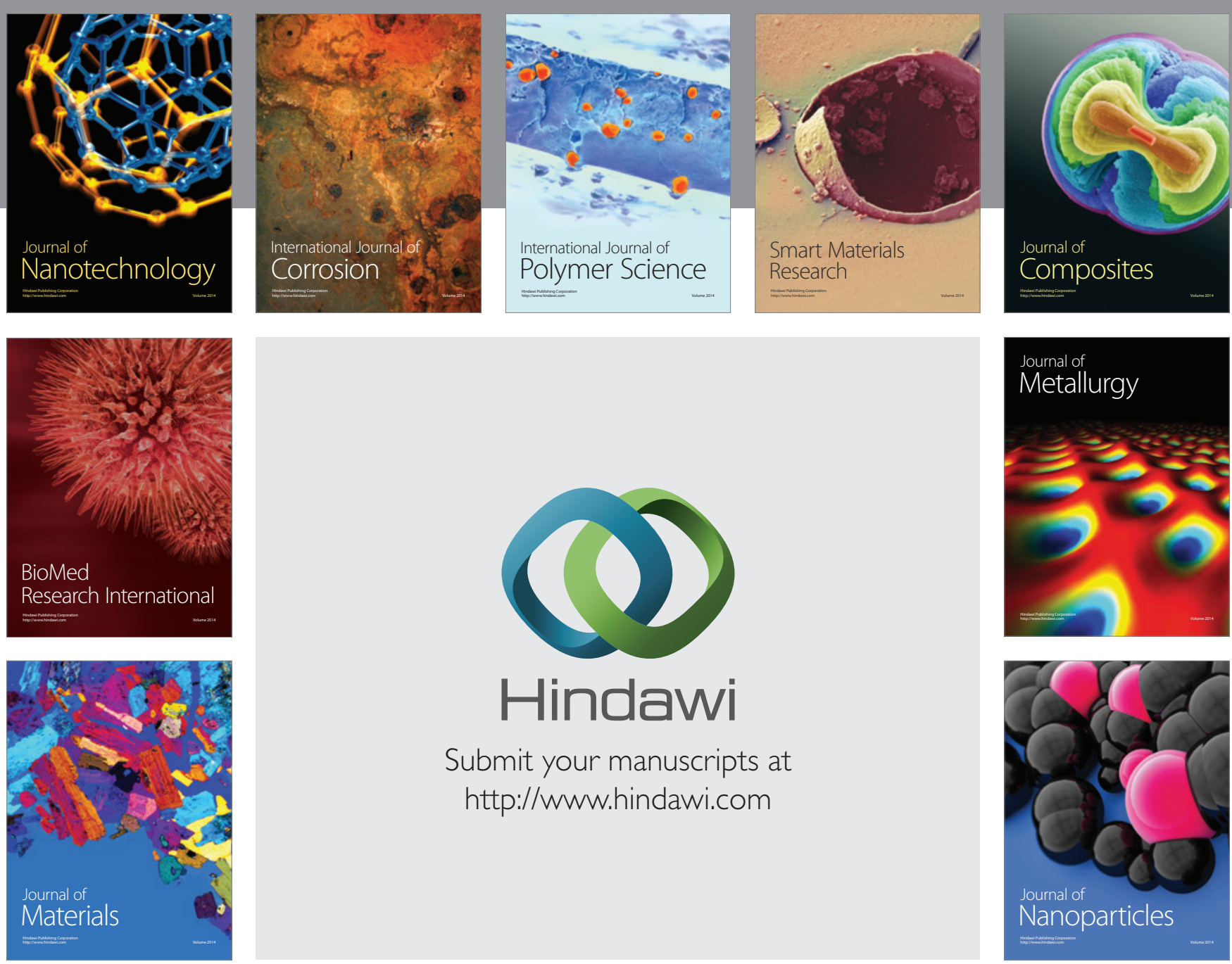

Submit your manuscripts at http://www.hindawi.com
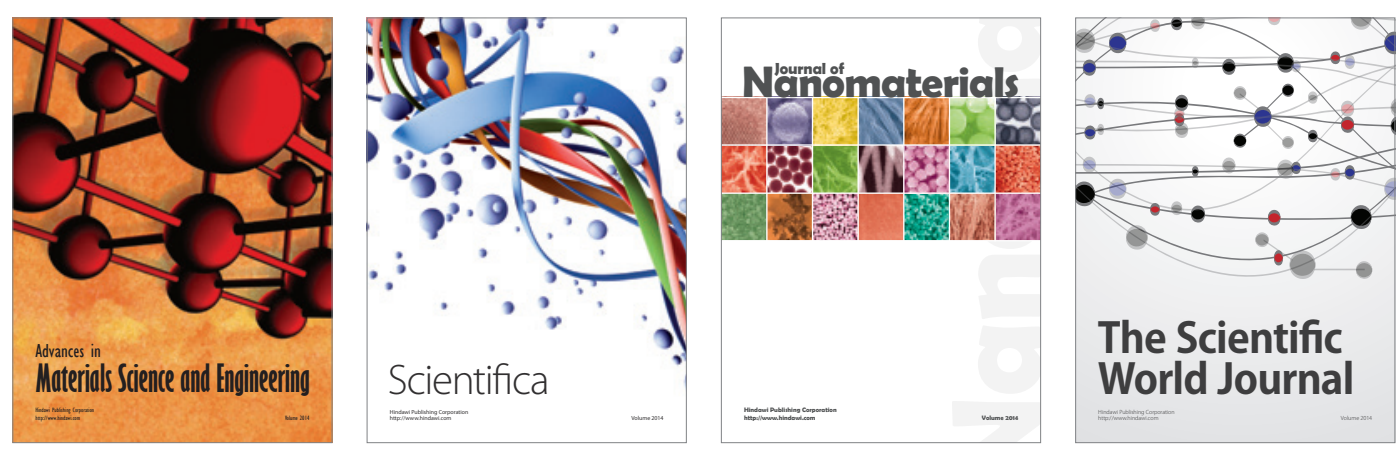

\section{The Scientific World Journal}
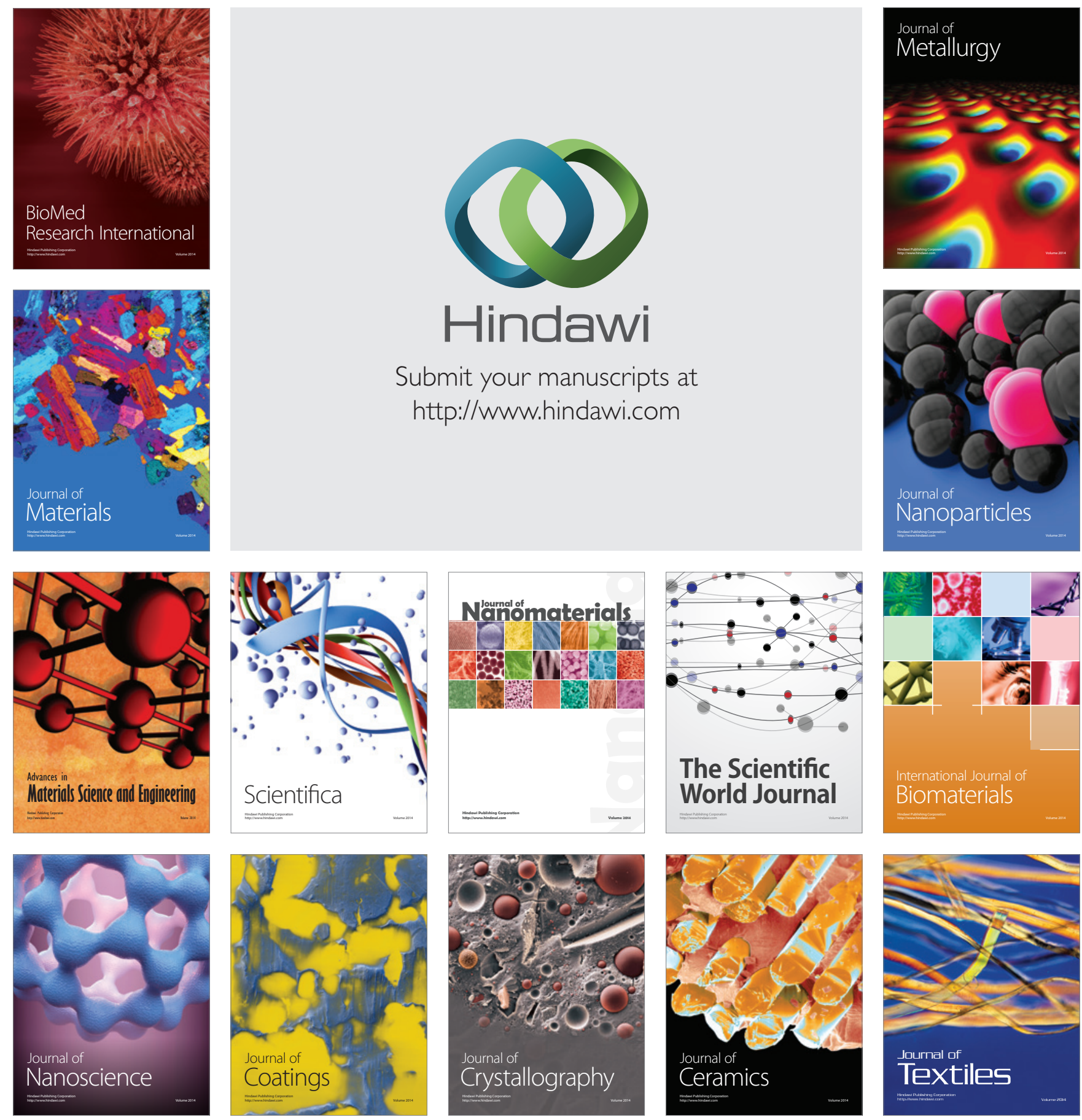